Molecules 2008, 13, 2169-2180; DOI: 10.3390/molecules13092169

Article

\title{
Phytochemical Contents and Antioxidant Capacities of Two Aloe greatheadii var. davyana Extracts
}

\section{Lisa Botes ${ }^{1}$, Francois H. van der Westhuizen ${ }^{2}$ and Du Toit Loots ${ }^{1,2, *}$}

1 School for Physiology, Nutrition and Consumer's Science, Private Bag X6001, Box 594, Potchefstroom, 2531, South Africa; E-mail: 12167398@nwu.ac.za (Lisa Botes)

2 School for Physical and Chemical Sciences, North-West University, Private Bag X6001, Box 269, Potchefstroom, 2531, South Africa; E-mails: francois.vanderwesthuizen@nwu.ac.za (Francois H. van der Westhuizen)

* Author to whom correspondence should be addressed; E-mail: dutoit.loots@nwu.ac.za; Tel.: +27182991818; Fax: +27182991818.

Received: 10 June 2008; in revised form: 22 August 2008 / Accepted: 23 August 2008 / Published: 12 September 2008

\begin{abstract}
Aloe greatheadii var. davyana (Asphodelaceae) is used among rural South African communities to treat arthritis, skin cancer, burns, eczema, psoriasis, digestive problems, high blood pressure and diabetes, despite very little supporting scientific evidence. Due to increased interest by both the scientific community and industry regarding the medicinal uses of this plant species, we identified, quantified and compared the phytochemical contents and antioxidant capacities of two extracts of A. greatheadii; a leaf gel extract (LGE) and a $95 \%$ aqueous ethanol leaf gel extract (ELGE), using various modified extraction procedures, GC-MS and spectrophotometry. Apart from extensively characterizing this medicinal plant with regards to its organic acid, polyphenols/phenolic acid, alcohol, aldehyde, ketone, alkane, pyrimidine, indole, alkaloid, phytosterol, fatty acid and dicarboxylic acid contents and antioxidant capacities, we describe a modified extraction procedure for the purpose of general phytochemical characterization, and compare this to a $95 \%$ aqueous ethanol extraction technique. From the results it is clear that $A$. greatheadii contains a variety of compounds with confirmed antioxidant capacity and other putative health benefits (such as blood glucose, cholesterol and cortisol lowering properties) relating to the prevention or treatment of diabetes, cardiovascular disease,
\end{abstract}


cancer and hypertension. The results also indicate that separate ethyl acetate/diethyl ether and hexane extractions of the LGE, better serve for general phytochemical characterization purposes, and $95 \%$ aqueous ethanol extraction for concentrating selective groups of health related compounds, hence justifying its use for biological in vivo efficacy studies.

Keywords: Phytochemical content; antioxidant capacity; polyphenols; phytosterols.

\section{Introduction}

Populations in developing countries worldwide rely heavily on the use of traditional medicine as their primary source of healthcare [1]. In South Africa alone over 27 million people use indigenous plant based medicines and up to $60 \%$ of the population consult with one of 200000 traditional healers [2]. Additionally, there is an increased global commercial interest in the use of these plant species for their proposed health benefits despite little or no scientific evidence justifying the anecdotal claims accompanying many of these products.

Aloes have been used therapeutically since ancient times $[3,4]$ and interest in the inner, colourless leaf gel has increased over the last two decades [5]. Partial characterization and biological action of various extracts of the leaf gel have been described, especially pertaining to diabetes [6]. The majority of the scientifically based research on this topic has to date, however, been done exclusively on two Aloe species namely; Aloe vera (or Aloe barbadensis) and Aloe arborescens. Aloe gel (from a variety of Aloe species) is sold commercially worldwide as an ingredient to a wide range of health care, cosmetic and therapeutic products [6]. This commercial activity, and widely distributed use of Aloe as used in traditional medicine, has led to an upsurge of both clinical and chemical research focusing on the active ingredients in these plants, as well as their biological activities.

The species of Aloe selected for commercial exploitation or selected by the traditional healer, would be based on its local availability and distribution. In South Africa the most widely distributed Aloe species are Aloe greatheadii var. davyana (Asphodelaceae) and Aloe ferox Mill. (Asphodelaceae). A. greatheadii grows wild in the northern parts of South Africa, whereas A. ferox grows wild primarily in the Eastern and Western Cape provinces. Various extracts of these Aloe species are traditionally used and commercially sold as creams, ointments and tonics for the purpose of treating a variety of ailments, of which their applications to arthritis, skin cancer, burns, eczema, psoriasis, digestive problems, high blood pressure and diabetes are most common. There is, however, very little or no scientific evidence to support these claims, with many of the claims being based on research done on A. vera. As different Aloe species would have varying phytochemical contents due to inter-species variation, and varying climate and soil conditions, direct correlation of biological activity would be inaccurate. Consequently, it is of relevance for scientists, industry and rural communities to not only research the relevant medicinal uses of these indigenous Aloe species, but also to determine the active components and their individual or combined mechanisms of biological function.

This paper will primarily focus on identifying, quantifying and comparing the phytochemical composition of two A. greatheadii var. davyana extracts: a leaf gel extract (LGE) and a $95 \%$ aqueous ethanol leaf gel extract (ELGE), obtained using a modified extraction procedure, and analysis on GC- 
MS and spectrophotometry. This is done in order to determine whether this plant species contains any individual compound or group of compounds which may substantiate its current commercial and traditionally use as a herbal medicine, in addition to determining the most appropriate methods of extracting these compounds. The results will consequently be discussed in the light of their putative biological or therapeutic relevance.

\section{Results and Discussion}

The individual compounds identified via GC-MS in the LGE and ELGE of $A$. greatheadii var. davyana are arranged according to their structural classifications and summarized in Table 1. Of the individual compounds identified, those best described for their health benefits include the polyphenols/phenolic acids, sterols, fatty acids and indoles. Other compounds identified include various alkanes, pyrimidines, alkaloids, organic acids, aldehydes, dicarboxylic acids, ketones and alcohols.

Table 1. Concentrations of GC-MS Identified Compounds from Lyophilized Aloe greatheadii var davyana Leaf Gel (LGE) And 95\% Aqueous Ethanol Leaf Gel Extracts (ELGE).

\begin{tabular}{|c|c|c|c|c|c|c|c|}
\hline \multirow[b]{2}{*}{ Compounds } & \multicolumn{3}{|c|}{ Concentration (ppm) } & \multirow[b]{2}{*}{ Compounds } & \multicolumn{3}{|c|}{ Concentration (ppm) } \\
\hline & LGE & $\begin{array}{c}\text { ELGE } \\
\text { (per dry } \\
\text { mass LGE) }\end{array}$ & $\begin{array}{c}\text { ELGE } \\
\text { (per dry mass } \\
\text { ELGE) } \\
\end{array}$ & & LGE & $\begin{array}{c}\text { ELGE } \\
\text { (per dry } \\
\text { mass LGE) }\end{array}$ & $\begin{array}{c}\text { ELGE } \\
\text { (per dry mass } \\
\text { ELGE) } \\
\end{array}$ \\
\hline Organic acids & & & & Alcohols & & & \\
\hline Isovaleric & 119 & 71.7 & $2.60 \times 10^{3}$ & 1-Propanol & 83.9 & - & - \\
\hline Pentanoic & 491 & 40.0 & $1.50 \times 10^{3}$ & 2,3-Butanol & 262 & - & - \\
\hline Lactic & 2786 & 111 & $4.10 \times 10^{3}$ & 2-Methyl-1,3-propanediol & 293 & - & - \\
\hline 2-Hydroxyacetic & 68.5 & - & - & Phenylethanol & 51.5 & - & - \\
\hline Pyruvic & 23.1 & 2.56 & - & Benzyl alcohol & 56.3 & 133 & $4.90 \times 10^{3}$ \\
\hline Furancarboxylic & 30.3 & - & - & 2,3-Pentanediol & 7.46 & - & - \\
\hline Oxalic & 0.88 & - & - & Glycerol & 1.20 & - & - \\
\hline 3-Hydroxypropanoic & 0.99 & - & - & Octadecanol & 11.9 & - & - \\
\hline 2-Hydroxyvaleric & 83.6 & 43.7 & $1.60 \times 10^{3}$ & Phytol & 20.1 & - & - \\
\hline Cyclohexane-3-carboxylic & 0.87 & - & - & 2-Methyl-1,3-butanol & - & 20.6 & $7.60 \times 10^{2}$ \\
\hline 3-Hydroxyisovaleric & 110 & - & - & Hexanol & 23.3 & - & - \\
\hline 2-Ketoisovaleric & 1.20 & 39.9 & $1.50 \times 10^{3}$ & Butanol & 6.45 & - & - \\
\hline Succinic & 415 & 989 & $3.70 \times 10^{4}$ & & & & \\
\hline 2-Methylsuccinic & 61.8 & 75.1 & $2.80 \times 10^{3}$ & Aldehydes & & & \\
\hline Methylmalic & 10.4 & - & - & Benzaldehyde & 35.3 & 156 & $5.80 \times 10^{3}$ \\
\hline Malic & 25.4 & 126 & $4.70 \times 10^{3}$ & $m$-Tolualdehyde & 11.7 & - & - \\
\hline Threonic & 1.43 & - & - & $p$-Tolualdehyde & - & 45.9 & $1.70 \times 10^{3}$ \\
\hline 3,4,5-Trihydroxypentanoic & 2.05 & - & - & 2,3-Dihydroxybenzaldehyde & 0.24 & - & - \\
\hline
\end{tabular}


Table 1. Cont.

\begin{tabular}{|c|c|c|c|c|c|c|c|}
\hline 2,3,4,5-Tetrahydroxypentanoic & - & 27.9 & $1.00 \times 10^{3}$ & Glyceraldehyde & 32.2 & - & - \\
\hline Suberic & 6.37 & - & - & & & & \\
\hline 3-Hydroxypicolinic & 34.9 & - & - & Ketones & & & \\
\hline Isonicotinic & 27.6 & - & - & 2,6-Dimethyl-4-heptanone & 153 & - & - \\
\hline 2-Ketoglutaric & - & 25.5 & $9.40 \times 10^{2}$ & 4,6-Dimethyl-2-heptanone & 34.5 & - & - \\
\hline Glycolic & - & 132 & $4.90 \times 10^{3}$ & Heptanone & - & 8.51 & $3.4 \times 10^{2}$ \\
\hline 3-Hydroxypropionic & - & 2.31 & $8.50 \times 10^{1}$ & & & & \\
\hline Methylbenzyl acetate & - & 16.7 & $6.20 \times 10^{2}$ & Pyrimidines & & & \\
\hline Acetic & - & 29.2 & $1.10 \times 10^{3}$ & Uracil & 554 & 919 & $3.40 \times 10^{4}$ \\
\hline Phosphoric & - & 233 & $8.60 \times 10^{3}$ & Thymine & 428 & 187 & $6.90 \times 10^{3}$ \\
\hline Hydantoinpropionic & - & 17.5 & $6.50 \times 10^{2}$ & & & & \\
\hline 2-Butoxyethylacetate & - & 57.6 & $2.10 \times 10^{3}$ & Indoles & & & \\
\hline Citric & - & 5.94 & $2.20 \times 10^{2}$ & Indole-5-acetic & 9.19 & - & - \\
\hline 2-Hydroxyglutaric & - & 24.8 & $9.20 \times 10^{2}$ & Hexahydrobenzoindole & - & 11.4 & $4.20 \times 10^{2}$ \\
\hline Tartaric & - & 9.69 & $3.60 \times 10^{2}$ & & & & \\
\hline \multirow[t]{2}{*}{ 3-Methylvaleric } & - & 58.6 & $2.20 \times 10^{3}$ & Alkaloids & & & \\
\hline & & & & Hypoxanthine & 33.1 & - & - \\
\hline \multicolumn{8}{|c|}{ Polyphenols / Phenolic compounds } \\
\hline Phenol & 11.8 & 46.0 & $1.70 \times 10^{3}$ & Phytosterols & & & \\
\hline 4-Ethylphenol & 5.85 & - & - & Cholestanol & 17.7 & - & - \\
\hline Vanillic & 60.7 & 25.7 & $9.50 \times 10^{2}$ & Campesterol & 119 & - & - \\
\hline Homovanillic & 23.4 & - & - & $\beta$-sitosterol & 99.6 & - & - \\
\hline Gentisic & 55.6 & - & - & Stigmasterol & 15.8 & - & - \\
\hline 6,7-Dihydroxycoumaric & 31.3 & - & - & & & & \\
\hline$o$-Hydroxycinnamic & 51.3 & - & - & Fatty acids & & & \\
\hline Protocatechuic & 162 & 42.7 & $1.60 \times 10^{3}$ & Lauric (C12:0) & 0.35 & - & - \\
\hline 3,4-Dihydroxyphenylacetic & 2.76 & - & - & Tridecanoic (C13:0) & 0.02 & - & - \\
\hline Syringic & 14.4 & - & - & Sebacic (C10:0) & 0.01 & - & - \\
\hline Sinapic & 37.8 & - & - & Myristic (C14:0) & 2.86 & - & - \\
\hline Caffeic & 107 & - & - & Undecanoic (C11:0) & 0.03 & - & - \\
\hline Isoferulic & 38.4 & - & - & Pentadecanoic (15:0) & 1.16 & - & - \\
\hline Ferulic & 60.1 & - & - & Palmitic (C16:0) & 43.0 & 1.49 & $5.50 \times 10^{1}$ \\
\hline Benzoic & 420 & 3136 & $1.20 \times 10^{5}$ & Stearic $(\mathrm{C} 18: 0)$ & 3.24 & - & - \\
\hline Phenylacetic & 71.3 & 283 & $1.00 \times 10^{4}$ & Nonadecanoic (C19:0) & 3.14 & - & - \\
\hline 2-Methoxybenzoic & 233 & - & - & Heneicosanoic (C21:0) & 0.28 & - & - \\
\hline$o$-Toluic & 162 & - & - & Behenic (C22:0) & 5.39 & - & - \\
\hline Phenylpropionic & 37.5 & 20.3 & $7.50 \times 10^{2}$ & Tricosanoic $(\mathrm{C} 23: 0)$ & 1.74 & - & - \\
\hline 4-Phenyllactic & 613 & 86.8 & $3.20 \times 10^{3}$ & Lignoceric (C24:0) & 5.11 & - & - \\
\hline 4-Hydroxybenzoic & 223 & 56.1 & $2.10 \times 10^{3}$ & Arachidonic (C20:4) & 0.57 & - & - \\
\hline 2,3-Hydroxybenzoic & 12.1 & - & - & Myristoleic (C14:1) & 0.20 & - & - \\
\hline 4-Hydroxyphenylacetic & 378 & 45.7 & $1.70 \times 10^{3}$ & 10-Pentadecenoic (C15:1) & 1.44 & - & - \\
\hline
\end{tabular}


Table 1. Cont.

\begin{tabular}{|c|c|c|c|c|c|c|c|}
\hline Hydro-p-coumaric & 13.9 & - & - & Palmitoleic (C16:1) & 4.00 & - & - \\
\hline$p$-Coumaric & 113 & - & - & Linoleic (C18:2 n-6) & 570 & - & - \\
\hline 3-Hydroxyphenylbutyric & - & 13.8 & $5.10 \times 10^{2}$ & 10-Heptadecenoic (C17:1) & 0.48 & - & - \\
\hline 4-Hydroxymandelic & - & 110 & $4.10 \times 10^{3}$ & Oleic (C18:1) & 30.1 & - & - \\
\hline Benzylacetate & - & 64.6 & $2.40 \times 10^{3}$ & & & & \\
\hline 2-Hydroxybutyric & - & 0.76 & $2.70 \times 10^{1}$ & Dicarboxylic acids & & & \\
\hline \multirow[t]{2}{*}{ Phenylpyruvic } & - & 9.41 & $3.40 \times 10^{2}$ & Azelaic & 0.04 & - & - \\
\hline & & & & 1,2-Benzenedicarboxylic & - & 29.5 & $1.10 \times 10^{3}$ \\
\hline \multicolumn{8}{|l|}{ Alkanes } \\
\hline 1,3-Dihydroxybutane & 8.51 & - & - & & & & \\
\hline
\end{tabular}

As shown in Table 1, the individual phenolic compounds identified in the highest concentrations in A. greatheadii LGE include 4-phenyllactic acid, benzoic acid, 4-hydroxyphenylacetic acid, 4-hydroxybenzoic acid and 4-methoxymandelic acid. Of the phenolic compounds best known for their health benefits and associated antioxidant properties, 4-hydroxyphenylacetic acid, 2,3-dihydroxybenzoic acid, protocatechuic acid, $p$-coumaric acid and caffeic acid were the most abundant. Of the four phytosterols identified, campesterol and $\beta$-sitosterol were by far the most abundant. Only one indole, indole-5acetic acid, was however identified in the LGE. Comparatively, higher concentrations of the above mentioned polyphenols were also detected in the ELGE (when quantified as per dry mass ELGE). Different to the ethyl acetate/diethyl ether extracts of the LGE, however, hexahydrobenzoindole was the only indole identified in the ELGE, and surprisingly, no phytosterols were detected in this extract.

As shown in Table 2, ORAC and FRAP analyses of LGE and ELGE revealed the ELGE to have greater antioxidant capacity compared to the LGE, which is supported by the higher total polyphenol contents detected in ELGE. The majority of the polyphenols in both the LGE and ELGE, as identified by GC-MS and confirmed spectrophometrically, are non-flavonoids, making-up $83.8 \%$ of the total polyphenol content of the LGE and $92.4 \%$ of the ELGE. An interesting phenomenon was the absence of Aloe-emodin in the A. greatheadii extracts. This is of importance as many of the health benefits associated with other Aloe species (including similar leaf gel extracts of $A$. ferox, also indigenous to South Africa), are attributed to the presence of, amongst other compounds, Aloe-emodin [7]. Finally, the total sugar contents of these extracts were $5.43 \mathrm{~g} / 100 \mathrm{~g}$ for the LGE and $83.76 \mathrm{~g} / 100 \mathrm{~g}$ for the ELGE, $36 \%$ of which was quantified as glucose, $18 \%$ as fructose and the remainder as maltose and sucrose.

We previously reported on the phytochemical composition and antioxidant capacities of $A$. ferox LGE and ELGE [7]. Compared to this species, A. greatheadii generally shows less variety and lower concentrations of the above mentioned health-associated antioxidant compounds. Similarly, Table 2 indicates the total polyphenol and non-flavonoid contents, as well as the antioxidant capacities of $A$. greatheadii LGE and ELGE, as measured by FRAP, to be lower than that as previously reported for $A$. ferox. The total flavonoid contents and the antioxidant capacities of $A$. greatheadii LGE, as measured by ORAC, were however higher comparatively, which may be indicative of the types of polyphenols in A. greatheadii having stronger scavenging ability than ferric ion reducing potential. Apart from 
inter-species variation explaining these differences, soil conditions and climate may also play a role in the varying phytochemical contents of these plants.

Table 2. Concentrations of Total Polyphenols, Flavonoids, Non-Flavonoids, Oxygen Radical Absorbance Capacity (ORAC) and Ferric Reducing Antioxidant Power (FRAP) in Lyophilized Aloe greatheadii var davyana Leaf Gel (LGE) and 95\% Aqueous Ethanol Leaf Gel Extracts (ELGE).

\begin{tabular}{|c|c|c|c|c|c|}
\hline Compound & $\begin{array}{c}\text { LGE } \\
\text { (dry mass) }\end{array}$ & $\begin{array}{c}\text { LGE } \\
\text { (wet mass) }\end{array}$ & $\begin{array}{c}\text { ELGE } \\
\text { (expressed as dry } \\
\text { mass ELGE) } \\
\end{array}$ & $\begin{array}{c}\text { ELGE } \\
\text { (expressed as dry } \\
\text { mass LGE) } \\
\end{array}$ & $\begin{array}{c}\text { ELGE } \\
\text { (expressed as wet } \\
\text { mass LGE) }\end{array}$ \\
\hline Total polyphenols (mg of GAE $/ 100 \mathrm{~g} \pm \mathrm{SD}$ ) & $45.1 \pm 0.94$ & $1.20 \pm 0.03$ & $263 \pm 6.51$ & $30.9 \pm 0.77$ & $0.82 \pm 0.02$ \\
\hline Total flavonoids (mg of CE/100g $\pm \mathrm{SD}$ ) & $7.66 \pm 0.26$ & $0.20 \pm 0.01$ & $20.2 \pm 0.50$ & $2.37 \pm 0.06$ & $0.06 \pm 0.001$ \\
\hline Total non-flavonoids (by calculation) & $37.8 \pm 0.99$ & $0.99 \pm 0.03$ & $243 \pm 6.96$ & $28.6 \pm 0.82$ & $0.75 \pm 0.02$ \\
\hline ORAC - hydrophyllic ( $\mu \mathrm{mol}$ of TE/g) & $59.0 \pm 1.16$ & $2.05 \pm 0.4$ & $83.0 \pm 1.32$ & $5.42 \pm 1.21$ & $0.19 \pm 0.04$ \\
\hline ORAC - lipophyllic ( $\mu \mathrm{mol}$ of TE/g) & - & - & - & - & - \\
\hline ORAC - total $(\mu \mathrm{mol}$ of $\mathrm{TE} / \mathrm{g})$ & $59.0 \pm 1.16$ & $2.05 \pm 0.4$ & $83.0 \pm 1.32$ & $5.42 \pm 1.21$ & $0.19 \pm 0.04$ \\
\hline FRAP $(\mu \mathrm{mol} / \mathrm{g})$ & $2.63 \pm 0.21$ & $0.09 \pm 0.01$ & $8.98 \pm 0.21$ & $0.58 \pm 0.01$ & $0.02 \pm 0.001$ \\
\hline
\end{tabular}

“-” denotes nothing detected.

From an analytical perspective, GC-MS analyses identified a larger number of compounds using direct LGE ethyl acetate/diethyl ether and hexane extractions, as compared to using the same extraction procedures on the ELGE, when quantified as per dry mass LGE (Table 1). This indicates that direct LGE ethyl acetate/diethyl ether and hexane extractions are best suited for general phytochemical characterization purposes. However, despite there being fewer compounds identified in the ELGE, the concentrations for many of the compounds with associated health benefits, and total sugars, were found to be between 1.2 to 1,250 times higher than the same compounds identified in the LGE, when expressed as per dry mass ELGE. This was further confirmed by the antioxidant capacity analyses showing higher activities in the latter extracts. This justifies the use of the latter approach for preparing extracts for use in in vivo or in vitro biological efficacy and mechanistic studies.

Epidemiological evidence supports the hypothesis that the consumption of foods rich in natural antioxidants plays an important role in the prevention of several chronic diseases associated with oxidative stress, including diabetes, cancer, hypertension and cardiovascular diseases [8]. Due to the fact that the majority of the phytochemicals identified in A. greatheadii were polyphenols/phenolic acids, one would expect these to be the major contributors to this plant's antioxidant capacity and its proposed use for alleviating or preventing diseases associated with oxidative stress $[9,10,11]$.

Considering that the mechanism proposed for developing diabetes is hyperglycaemia induced oxidative stress [5, 12-14], the current use of A. greatheadii in traditional and commercial tonics for treating this disease may be justified. To date, various authors have reported on the anti-diabetic properties of a variety of other Aloe species from both human and animal trials, of which Aloe vera and Aloe arborenscens are by far the best described. Interventions involving various extracts, including a $95 \%$ aqueous ethanol extract of these, have been shown to alleviate the diabetic state. By 
preventing hyperglycaemia induced oxidative stress and the associated pancreatic $\beta$-cell destruction, these plant extracts have been shown to increase insulin secretion by the pancreas, and in so doing correct the diabetes associated hyperglycaemia and dyslipidaemia [5, 12-14]. This action is ascribed to the various polyphenols present in these extracts, which alleviate the diabetic condition by lowering glucose uptake, and in doing so prevent hyperglycaemia [15, 16]. Additionally, the plant sterols identified in A. greatheadii also possess similar glucose lowering effects. Tanaka et al. (2006) reported reductions in both fasting and random blood glucose levels of $d b / d b$ diabetic mice chronically treated with the same phytosterols from A. vera leaf gel [17]. Apart from these glucose lowering effects, phytosterols are better known for their total cholesterol and low-density lipid cholesterol (LDL-C) lowering effects [18]. As summarized by Devaraj and Jialal [19], evidence for this has been observed in hypercholesterolemic, diabetic and healthy volunteers [19]. The mechanism proposed by which phytosterols accomplish this, is by lowering cholesterol absorption due to the structural similarities that these compounds share with cholesterol [20-22]. Apart from lowering cardiovascular risk factors associated with diabetes and other diseases, $\beta$-sitosterol has been shown to positively influence a diabetic state by directly lowering fasting blood glucose levels by cortisol inhibition [23]. Furthermore, phytosterols have been shown to reduce biomarkers for oxidative stress and inflammation [19], as well as to reduce cancer development by a variety of mechanisms [24]. Based on the presence of the high amounts of many of the same polyphenols and phytosterols in A. greatheadii LGE and ELGE, this Aloe species may show promise in preventing or alleviating the progression of diseases associated with oxidative stress, including diabetes, cancer, hypertension and cardiovascular diseases. On the other hand, the total sugar/glucose contents of these extracts may be of concern, especially when considering using these extracts in the context of a diabetes intervention, as carbohydrate intake is considered a major factor in glycaemic control. Nielsen and co-workers report that a low carbohydrate diet, containing $20 \%$ carbohydrates, is superior to a diet containing 55 - $60 \%$ carbohydrates, with regards to controlling bodyweight, blood glucose levels and reducing in $\mathrm{HbA}_{1 \mathrm{c}}$ [25]. The American Diabetes Association (ADA) defines a low carbohydrate diet as less than $130 \mathrm{~g} / \mathrm{d}$ or $26 \%$ of a nominal 2,000 kcal $(8,400 \mathrm{~kJ})$ diet [26]. Considering the above mentioned recommended carbohydrate intakes for diabetics and the mechanisms by which the pholyphenols and phytosterols elicit their anti-diabetic actions (by lowering glucose absorption and protecting pancreatic $\beta$-cells from oxidative destruction), the sugar contents of these extracts may not necessarily be problematic due to the small amounts that would be additionally ingested during an intervention using these extracts. This however should be investigated, in addition to other methods of extraction which could potentially eliminate these sugars.

\section{Conclusions}

Analytically, direct LGE ethyl acetate/diethyl ether and hexane extractions produce better phytochemical characterization, whereas $95 \%$ aqueous ethanol extraction concentrates a number of health related compounds, justifying its applications to in vivo efficacy studies. From a medicinal application perspective, A. greatheadii contains a variety of compounds (esp. polyphenols and phytosterols) with confirmed antioxidant capacity, and putative therapeutic actions (including blood glucose, cholesterol and cortisol lowering properties) relating to the prevention or treatment of diabetes, cardiovascular disease, cancer and hypertension. No toxic compounds were detected in these 
Aloe extracts, however, due the presence of other confounders which may have been missed in this study, further confirmation of the proposed health benefits of these extracts through in vivo animal experimentation is strongly suggested.

\section{Experimental}

\section{General}

All analytical standards and reagents used for quantification, and those used for generating mass spectra for GC-MS identification, were purchased from Sigma-Aldrich (St Louis, MO, USA). All organic extraction solvents used were of ultra high purity purchased from Burdick and Jackson (USA). Folin-Ciocalteu's phenol reagent and other reagent chemicals were purchased from Merck (Darmstadt, Germany).

\section{Plant material}

Whole, freshly cut, A. greatheadii var. davyana leaves $(100 \mathrm{~kg})$ were harvested from approximately 200 plants in the month of May (2007) from a rural area in the Potchefstroom district of the North West Province in South Africa (herbarium deposit site: AP Goossens Herbarium (code: PUC), Potchefstroom South Africa; voucher number : PUC 7951). All leaves were collected from mature plants with a circular diameter greater than $50 \mathrm{~cm}$.

\section{Sample preparation}

The leaf skin was removed by hand and the leaf gel homogenized, lyophilized and stored at $-20{ }^{\circ} \mathrm{C}$ until analysis. This was termed the leaf gel extract (LGE). A large portion of the LGE was used for the preparation of a $95 \%$ aqueous ethanol leaf gel extract (ELGE). Batches (420 g) of finely ground lyophilized Aloe gel were extracted using $95 \%$ aqueous ethanol $(500 \mathrm{~mL})$, followed by sonication for $10 \mathrm{~min}$ and shaking for 1 hour. The solvent was collected following centrifugation at $3000 \mathrm{x} \mathrm{g}$ for 10 min. This was repeated 10 times to ensure total extraction of all compounds from the lyophilized extracts. The supernatants were pooled and evaporated to dryness under reduced pressure in a rotary evaporator. The residue was stored in dry sterilized containers at $-20{ }^{\circ} \mathrm{C}$ until further use.

\section{Ethyl acetate/diethylether extraction}

3-Phenylbutyric acid $(5 \mathrm{mg} / \mathrm{mL}, 100 \mu \mathrm{L})$ was added as an internal standard to LGE and ELGE (25 $\mathrm{mg})$ followed by sodium acetate buffer $(0.125 \mathrm{M}, 1 \mathrm{~mL})$ and $\beta$-glucuronidase $(60 \mu \mathrm{L})$. Samples were then incubated at $37^{\circ} \mathrm{C}$ for 3 hours. Incubated samples were subsequently extracted with ethyl acetate $(6 \mathrm{~mL})$ followed by diethyl ether $(3 \mathrm{~mL})$. After centrifugation, collected supernatants were pooled and dried under a nitrogen stream. Derivatization with bis(trimethylsilyl) trifloroacetamide (BSTFA, 100 $\mu \mathrm{L}$ ), trimethylchlorosilane (TMCS, $20 \mu \mathrm{L})$ and pyridine $(20 \mu \mathrm{L})$ at $70{ }^{\circ} \mathrm{C}$ for $30 \mathrm{~min}$ followed. After cooling to room temperature, $0.1 \mu \mathrm{L}$ of the derivatized extract was injected into the GC-MS via splitless injection. 


\section{Hexane Extraction for Fatty Acids}

The internal standard, heptadecanoic acid (72 mM), was added to LGE and ELGE (25 mg) followed by a $45 \mathrm{mM}$ solution of butylated hydroxytoluene $(100 \mu \mathrm{L})$ and methanolic HCL $(3 \mathrm{~N}, 1 \mathrm{~mL})$. The samples were vortexed and incubated for 4 hours at $90{ }^{\circ} \mathrm{C}$. After cooling to room temperature, the samples were extracted twice with $2 \mathrm{ml}$ of hexane, dried under a nitrogen stream and finally resuspended with hexane $(100 \mu \mathrm{L}), 0.1 \mu \mathrm{L}$ of which was injected onto the GC-MS via splitless injection.

\section{Phytochemical Characterization via GC-MS}

An Agilent 6890 GC ported to a 5973 MS detector (California, USA) was used for identification and quantification of individual phytochemicals, using MS libraries previously compiled from purchased standards. For the acquisition of an electron ionization mass spectrum, an ion source temperature of $200{ }^{\circ} \mathrm{C}$ and electron energy of $70 \mathrm{eV}$ was used. The $\mathrm{GC}$ was equipped with a SE-30 capillary column (Chemetrix, USA), a split/splitless injection piece $\left(250{ }^{\circ} \mathrm{C}\right)$ and direct GC-MS coupling $\left(260^{\circ} \mathrm{C}\right)$. Helium $(1 \mathrm{~mL} / \mathrm{min})$ was used as the carrier gas. The oven temperature program for analyzing the ethyl acetate/diethylether extracts utilized an initial oven temperature of $40{ }^{\circ} \mathrm{C}$, maintained for $2 \mathrm{~min}$, followed by a steady climb to $350{ }^{\circ} \mathrm{C}$ at a rate of $5{ }^{\circ} \mathrm{C} / \mathrm{min}$. For the fatty acid analysis, hexane extracts were analyzed using an initial oven temperature of $50{ }^{\circ} \mathrm{C}$, maintained for 1.5 min, and then allowed to increase to $190{ }^{\circ} \mathrm{C}$ at a rate of $30{ }^{\circ} \mathrm{C} / \mathrm{min}$. This oven temperature was again maintained at $190{ }^{\circ} \mathrm{C}$ for $5 \mathrm{~min}$ and then allowed to increase to $220^{\circ} \mathrm{C}$ at a rate of $8{ }^{\circ} \mathrm{C} / \mathrm{min}$. This oven temperature was maintained for $2 \mathrm{~min}$ and finally ramped to $230{ }^{\circ} \mathrm{C}$ at a rate of $3{ }^{\circ} \mathrm{C} / \mathrm{min}$ and maintained for a further $24 \mathrm{~min}$.

\section{Total Polyphenols}

The total polyphenol contents of the LGE and ELGE were determined according to the FolinCiocalteu procedure [27]. Briefly, finely ground LGE or ELGE (10 mg) was dissolved in $\mathrm{H}_{2} \mathrm{O}(200$ $\mu \mathrm{L})$ in a test tube and Folin-Ciocalteu's reagent $(1 \mathrm{~mL})$ was added. This was allowed to stand for $8 \mathrm{~min}$ at room temperature. Next, sodium carbonate $(7.5 \%$, w/v, $0.8 \mathrm{~mL})$ was added, mixed and allowed to stand for $30 \mathrm{~min}$. Absorption was measured at $765 \mathrm{~nm}$ (Shimadzu UV-1601 Spectrophotometer). The mean total phenolic contents $(\mathrm{n}=3)$ were expressed as milligram gallic acid equivalents per $100 \mathrm{~g}(\mathrm{mg}$ GAE $/ 100 \mathrm{~g}$ dry mass or wet mass \pm standard derivatives).

\section{Total flavonoids}

The total flavonoid contents of the LGE and ELGE were measured using the aluminium chloride assay as described by Zhishen and co-workers with slight modifications [28]. Briefly, LGE or ELGE $(10 \mathrm{mg})$ was dissolved in $\mathrm{H}_{2} \mathrm{O}(1 \mathrm{~mL})$ in a test tube, to which $5 \%(\mathrm{w} / \mathrm{v}) \mathrm{NaNO}_{2}(60 \mu \mathrm{L})$ was added. After $5 \mathrm{~min}$, a $10 \%(\mathrm{w} / \mathrm{v}) \mathrm{AlCl}_{3}$ solution $(60 \mu \mathrm{L})$ was added. After $6 \mathrm{~min}, 1 \mathrm{M} \mathrm{NaOH}(400 \mu \mathrm{L})$ was added and the total volume made up to $2 \mathrm{~mL}$ with $\mathrm{H}_{2} \mathrm{O}$. The solution was mixed well and the absorbance measured at $510 \mathrm{~nm}$ against a reagent blank. Concentrations were determined using a catechin standard curve. Mean total flavonoid contents $(n=3)$ were expressed as milligrams catechin equivalents (CE) per $100 \mathrm{~g}$ (mg CE/100g dry or wet mass \pm standard deviation). 


\section{Oxygen Radical Absorbance Capacity (ORAC)}

ORAC analyses of hydrophilic and lipophylic fractions of the LGE and ELGE were performed essentially as described by Prior et al. [29]. The analyses of lipophylic compounds were aided by the addition of randomly methylated $\beta$-cyclodextrin (kind gift from Dr R Prior) as a solubility enhancer as described by Huang et al. [30]. Briefly, in a volume of $200 \mu \mathrm{L}$, the reaction contained $56 \mathrm{nM}$ fluorescein as a target for free radical attack by $240 \mathrm{nM}$ 2,2'-azobis(2-amidinopropane) dihydrochloride. A fluorescence plate reader (BioTEK FL-600, UK) was used and the decay of fluorescence of fluorescein (excitation $485 \mathrm{~nm}$, emission $520 \mathrm{~nm}$ ) was measured every 5 min for 2 hours at $37{ }^{\circ} \mathrm{C}$. Costar black opaque (96-well) plates were used in the assays. Trolox was used as a standard at a range of between 0-20 $\mu \mathrm{M}$, giving a polynomial (2nd order) curve fit analysis. Mean values $(n=3)$ of antioxidant capacities were expressed as $\mu$ mole trolox equivalents (TE) / g wet and dry mass \pm standard deviation.

\section{Ferric Reducing Antioxidant Power (FRAP)}

FRAP values of the LGE and ELGE were determined essentially as described previously [31]. Briefly, the reduction of a $\mathrm{Fe}^{3+}-2,3,5$-triphenyltetrazolium complex in the assay, by the antioxidants in the samples, was monitored at $593 \mathrm{~nm}$. As a standard, $\mathrm{FeSO}_{4}$ was used and the FRAP activities of the

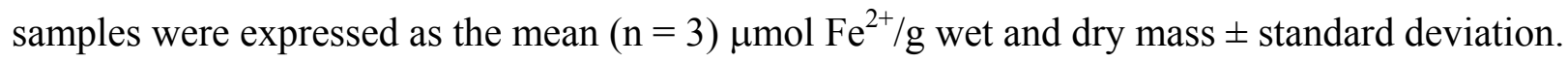

\section{Sugar content}

The total sugar content as well as the type of sugar present in the LGE and ELGE was determined at the Department of Agriculture, Directorate Food Safety and Quality Assurance, Division Analytical Services North, Pretoria, South Africa. The total sugar content was determined by Refractive index (RI) as previously described [32]. The concentrations of fructose and glucose were determined via HPLC using a Supelcosil LC-NH2 column (Supelco, 250 x $4.6 \mathrm{~mm}, 5 \mu \mathrm{m}$, Sigma-Aldrich Catalogue No: 58338 ) and $75 \%$ Acetonitrile as mobile phase with a flow rate of $1.5 \mathrm{~mL} / \mathrm{min}$ at $30^{\circ} \mathrm{C}$ and detected by a Refractive Index (RI) detector. The results are expressed as percentage sugars $(\mathrm{m} / \mathrm{m})$ in LGE and ELGE.

\section{References}

1. Cunningham, A.B.; African medical plants: setting priorities at the interface between conservation and primary healthcare. People and plants working paper 1. UNESCO: Paris, 1993; http://nsdl.loncapa.org/res/msu/botonl/b_online/library/peopleplants/wp/wp1/intro.htm [Date of access: 28 Feb. 2007].

2. Thring, T.S.A.; Weitz F.M. Medicinal plant use in the Bredasdorp/Elim region of the Southern Overberg in the Western Cape Province of South Africa. J. Ethnopharmacol. 2006, 103, 261275.

3. Morton, J.F. Folk uses and commercial exploitation of aloe leaf pulp. Econ. Botany 1961, 311 319. 
4. Crosswhite, F.S.; Crosswhite, C.D. Aloe vera, plant symbolism and the threshing floor. Desert Plants 1984, 6, 43-50.

5. Reynolds, T.; Dweck, A.C. Aloe vera leaf gel: a review update. J. Ethnopharmacol. 1999, 68, 337.

6. Rajasekaran, S.; Sivagnaman, K.; Subramanian, S. Modulatory effects of Aloe vera leaf gel extract on oxidative stress in rats treated with streptozotocin. J. Pharm. Pharmacol. 2005, 57, 241-246.

7. Loots, Du T.; Van der Westhuizen, F.H.; Botes, L. Aloe ferox leaf gel phytochemical content, antioxidant capacity and possible health benefits. J. Agric. Food. Chem. 2007, 55, 6891-6896.

8. Willcox, J.K.; Ash, S.L.; Catignami G.L. Antioxidants and the prevention of chronic disease. Crit. Rev. Food. Sci. Nutr. 2004, 44, 275-295.

9. Cao, G.; Sofic, E.; Prior, R.L. Antioxidant and prooxidant behavior of flavonoids: structureactivity relationships. Free. Radic. Biol. Med. 1997, 22, 749-760.

10. Herraiz, T.; Galisteo, J. Endogenous and Dietary Indoles: A Class of Antioxidants and Radical Scavengers in the ABTS Assay. Free. Radic. Res. 2004, 38, 323-331.

11. Scalbert, A.; Manach, C.; Morand, C.; Re'Me' Sy, C. Dietary polyphenols and the prevention of disease. Crit. Rev. Food. Sci. Nutr. 2005, 45, 287-306.

12. Agarwal, PO. Prevention of atheromatous heart disease. Angiology 1985, 36, 485-492.

13. Beppu, H.T.; Koike, K.; Shimpo, T.; Chihara, M.; Hoshino, C.I.; Kuzuya, H. Radical-scavenging effects of Aoe arborescens Miller on prevention of pancreatic islet $\beta$-cell destruction in rats. $J$. Ethnoparmacol. 2003, 89, 37-45.

14. Rajasekaran, S.; Sivagnaman, K.; Subramanian, S. Antioxidant effect of Aloe vera gel extract in streptozotocin-induced diabetes in rats. Pharmacol. Rep. 2005, 57, 90-96.

15. Cao, H.; Hininger-Favier, I.; Kelly, M.A.; Benaraba, R.; Dawson, H.D.; Coves, S.; Roussel, A.M.; Anderson, R.A. Green tea polyphenol extract regulates the expression of genes involved in glucose uptake and insulin signalling in rats fed a high fructose diet. J. Agric. Food. Chem. 2007, 55, 6372-6378.

16. Johnston, K.; Sharp, P.; Clifford, M.; Morgan, L. Dietary polyphenols decrease glucose uptake by human intestinal Caco-2 cells. Fed. Eur. Biochem. Soc. Lett. 2005, 579, 1653-7.

17. Tanaka, M.; Misawa, E.; Ito, Y.; Habara, N.; Nomaguchi, K.; Yamada, M.; Toida, T.; Hayasawa, H.; Takase, M.; Inagaki, M.; Higuchi, R. Identification of five phytosterols from aloe vera gel as anti-diabetic compounds. Biol. Pharm. Bull. 2006, 29, 1418-1422.

18. Patch, C.S.; Tapsell, L.C.; Williams, P.G.; Gordon, M. Plant sterols as dietary adjuvants in the reduction of cardiovascular risk: theory and evidence. Vasc. Health. Risk. Manag. 2006, 2, $157-$ 162.

19. Devaraj, S.; Jialal, I. The role of dietary supplementation with plant sterols and stanols in the prevention of cardiovascular disease. Nutr. Rev. 2006, 64, 348-354.

20. Lichtenstein, A.H.; Deckelbaum, R. AHA Science Advisory. Stanol/sterol ester-containing foods and blood cholesterol levels. A statement for healthcare professionals from the Nutrition Committee of the Council on Nutrition, Physical Activity, and Metabolism of the American Heart Association. Circulation 2001, 103, 177-1179. 
21. Normen, L.; Dutta, P.; Lia, A.; Andersson, H. Soy sterol esters and beta-sitostanol ester as inhibitors of cholesterol absorption in human small bowel. Am. J. Clin. Nutr. 2000, 71, 908-913.

22. Jones, P.J.; Ntanios, F.Y.; Raeini-Sarjaz, M.; Vanstone, C.A. Cholesterol-lowering efficacy of a sitostanol-containing phytosterol mixture with a prudent diet in hyperlipidemic men. Am. Clin. Nutr. 1999, 69, 1144-1150.

23. McAnuff, M.A.; Harding, W.W.; Omoruyi, F.O.; Jacobs, H.; Morrison, E.Y.; Asemota, H.N. Hypoglycemic effects of steroidal sapogenins isolated from Jamaican bitter yam, Dioscorea polygonoides. Food. Chem. Toxicol. 2005, 43, 1667-1672.

24. Bradford, P.G.; Awad, A.B. Phytosterols as anticancer compounds. Mol. Nutr. Food. Res. 2007, 51, 161-170.

25. Nielsen, J.V.; Jönsson, E.A. Low-carbohydrate diet in type 2 diabetes. Stable improvement of body weight and glycaemic control during 22 months follow-up. Nutr. Metab. (Lond). 2006, $3: 22,1-5$.

26. American Diabetes Association. Nutrition recommendations and interventions for diabetes. Diabet. Care 2007, 30(Suppl 1), S48-S65

27. Singleton, V.L.; Rossi, J.A. Colorimetry of total phenolics with phosphomolybdicphosphostungastic acid reagents. Am. J. Enol. Vitic. 1965, 16, 144-158.

28. Marinova, D.; Robarova, F.; Atanassova, M. Total phenolics and total flavonoids in bulgarian fruits and vegetables. J. Univ. Chem. Technol. Metall. 2005, 40, 255-260.

29. Prior, R.L.; Hoang, H.; Gu, L.; Wu, X.; Bacchiocca, M.; Howard, L.; Hampsch-Woodill, M.; Huang, D.M.; Ou, B.; Jacob, R. Assays for hydrophilic and lipophilic antioxidant capacity (ORAC(FL)) of plasma and other biological and food samples. J. Agric. Food. Chem. 2003, 51, 3273-3279.

30. Huang, D.; Ou, B.; Hampsc-Woodill, M.; Flanagan, J.A.; Deemer, E.K. Development and validation of oxygen radical absorbance capacity assays for lipophilic antioxidants using randomly methylated beta-cyclodextrin as the solubility enhancer. J. Agric. Food. Chem. 2002, 27, 1815-1821.

31. Benzie, I.F.; Strain, J.J. Ferric reducing/antioxidant power assay: direct measure of total antioxidant activity of biological fluids and modified version for simultaneous measurement of total antioxidant power and ascorbic acid concentration. Meth. Enzymol. 1999, 299, 15-27.

32. Stevens, J.W.; Baier, W.E. Corrections for obtaining soluble solids from refractometer readings (soluble solids as sucrose). Ind. \& Eng. Chem., Anal. Ed. 11 1939, 447-449.

C 2008 by the authors; licensee Molecular Diversity Preservation International, Basel, Switzerland. This article is an open-access article distributed under the terms and conditions of the Creative Commons Attribution license (http://creativecommons.org/licenses/by/3.0/). 